BMJ Open

Diabetes

Research

\& Care

\title{
Early pregnancy plasma fatty acid profiles of women later diagnosed with gestational diabetes
}

\author{
Ellen Alma Tryggvadottir (D) ,,2 Ingibjorg Gunnarsdottir, ${ }^{1,2}$ \\ Bryndis Eva Birgisdottir, ${ }^{1,2}$ Laufey Hrolfsdottir, ${ }^{1,3}$ Rikard Landberg, ${ }^{4}$ \\ Ingibjorg Th Hreidarsdottir, ${ }^{5,6}$ Hildur Hardardottir, ${ }^{6}$ Thorhallur Ingi Halldorsson ${ }^{1,2}$
}

To cite: Tryggvadottir EA, Gunnarsdottir I, Birgisdottir BE, et al. Early pregnancy plasma fatty acid profiles of women later diagnosed with gestational diabetes. BMJ Open Diab Res Care 2021;9:e002326. doi:10.1136/ bmjdrc-2021-002326

- Supplemental material is published online only. To view, please visit the journal online (http://dx.doi.org/10.1136/ bmjdrc-2021-002326).

Received 12 April 2021 Accepted 4 July 2021

Check for updates

\section{(C) Author(s) (or their} employer(s)) 2021. Re-use permitted under CC BY-NC. No commercial re-use. See rights and permissions. Published by BMJ.

${ }^{1}$ Faculty of Food Science and Nutrition, University of Iceland, Reykjavik, Iceland

${ }^{2}$ Unit for Nutrition Research, Landspitali University Hospital, Reykjavík, Iceland

${ }^{3}$ Department of Education and Science, Akureyri Hospital, Akureyri, Iceland

${ }^{4}$ Biology and Biological Engineering, Chalmers University of Technology, Goteborg, Sweden

${ }^{5}$ Department of Obstetrics and Gynecology, Landspítali University Hospital, Reykjavík, Iceland

${ }^{6}$ Faculty of Medicine, University of Iceland, Reykjavik, Iceland

Correspondence to Ellen Alma Tryggvadottir; eat2@hi.is

\section{ABSTRACT}

Introduction Fatty acid (FA) concentrations have previously been associated with gestational diabetes mellitus (GDM). However, few studies on GDM have examined FA profiles in early pregnancy or before diagnosis. This study aimed to compare early pregnancy plasma FA profiles of women with and without GDM diagnoses as well as their reported dietary consumption. Research design and methods The subjects comprised 853 women from the prospective study: Pregnant Women in Iceland II (PREWICE II), attending their 11-14 weeks ultrasound appointment in 2017-2018. During the visit, blood samples were collected for plasma FA analysis, and dietary habits were assessed using a short food frequency questionnaire. Information on GDM diagnoses was then later extracted from medical records. Differences in FA profile between GDM cases and non-cases were evaluated using the Mann-Whitney U test.

Results GDM was diagnosed in 127 women (14.9\%). Concentrations of saturated fatty acids, monounsaturated fatty acids, polyunsaturated fatty acids (PUFA) $n-6$, PUFA $n-3$ and total FA were higher in the women who later developed GDM compared with those who did not $(\mathrm{p} \leq 0.05)$. The medians for total FA were $2898 \mu \mathrm{g} / \mathrm{mL}$ for the women with GDM and $2681 \mu \mathrm{g} / \mathrm{mL}$ for those without GDM. Mean adjusted difference for total FA between the groups was $133 \mu \mathrm{g} / \mathrm{mL}$ (95\% Cl 33 to 233). Similar results were observed in prepregnancy normal-weight women and overweight women/women with obesity. Overall diet quality in early pregnancy appeared to be lower among the women later diagnosed with GDM.

Conclusion We found that plasma FA profiles in early pregnancy were different for women later diagnosed with GDM compared with those who were not, independent of the women's body mass index.

\section{INTRODUCTION}

Gestational diabetes mellitus (GDM) is one of the most common pregnancy complications and a strong risk factor for later development of type 2 diabetes (T2D). ${ }^{1}$ Potential risk factors for GDM include prepregnancy overweight and obesity, age and unhealthy dietary habits. ${ }^{2}$ With respect to dietary fat intake, high maternal intake of total fat, ${ }^{3}$ saturated fatty acids (SFA) as well as cholesterol ${ }^{4}$

\section{Significance of this study}

What is already known about this subject?

- Fatty acid (FA) profiles have been associated with gestational diabetes; however, most studies were performed during or after gestational diabetes mellitus (GDM) diagnoses and few have additionally investigated dietary intake.

What are the new findings?

- Plasma FA profiles in early pregnancy were different for women with and without GDM diagnoses later in pregnancy.

- Differences in plasma FA profiles were independent of the women's body mass index.

- Women that were later diagnosed with GDM appeared to have lower overall diet quality in early pregnancy.

How might these results change the focus of research or clinical practice?

- Further research is needed on early pregnancy FA profiles as a predicter for GDM.

- Increased dietary quality during pregnancy should be a clinical focus in GDM prevention.

have previously been associated with an increased risk of GDM, ${ }^{35}$ whereas intake of polyunsaturated fatty acid (PUFA) and alphalinolenic acid (ALA) has been associated with reduced risk. ${ }^{6}$ Circulating FA can derive from both dietary intake ${ }^{7}$ and catabolism or endogenous synthesis, both of which being partly influenced by glucose homeostasis. As an example, free fatty acid (FFA) levels have been associated with altered secretion of insulin as well as insulin resistance (IR), which may progress to diabetes. ${ }^{9-12}$

In most previous studies on FA profiles in pregnant cohorts, FA analysis was performed during or after GDM diagnoses, ${ }^{12}$ whereas few studies have investigated the FA profile during the first trimester, before GDM diagnoses. ${ }^{13-17}$ Their results indicated that women 


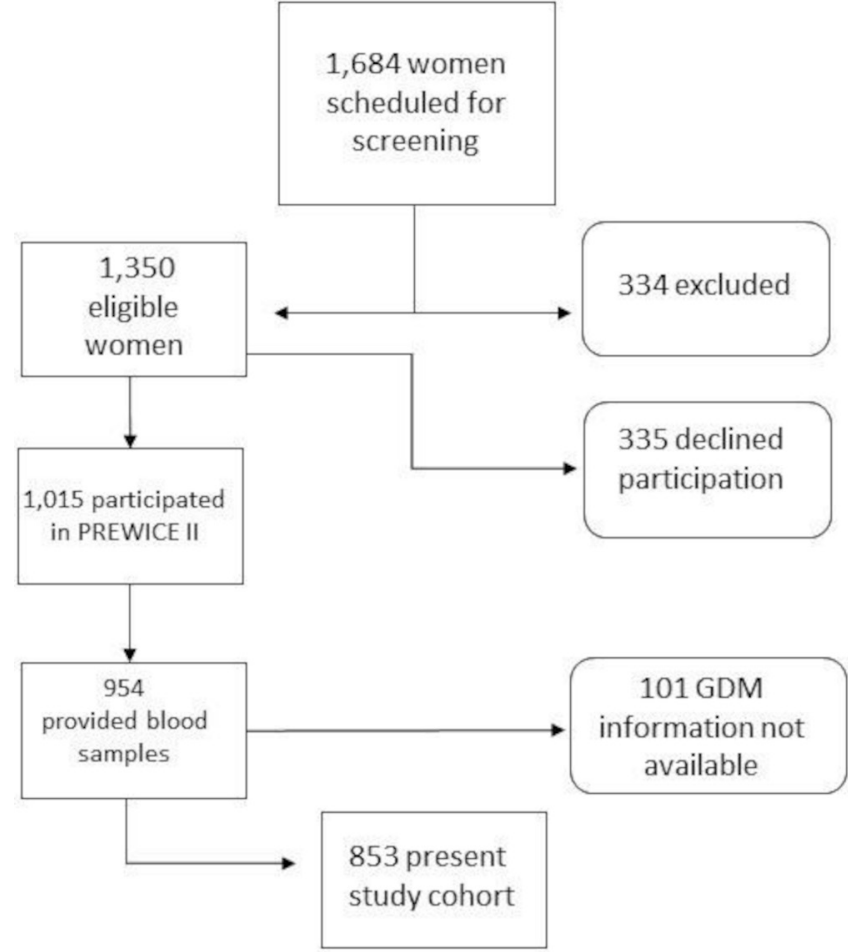

Figure 1 Participant flow chart. GDM, gestational diabetes mellitus; PREWICE II, Pregnant Women in Iceland II.

diagnosed later with GDM had higher total concentrations of SFA, ${ }^{13-15}$ MUFA, ${ }^{13}{ }^{15}$ PUFA $n-6^{16}$ and PUFA n- $3^{13}$ and sometimes lower concentrations of PUFA $n-6^{1315}$ and PUFA n-3..$^{15-17}$

Our aim was to investigate whether the total plasma FA profile during the first trimester was associated with increased odds of GDM diagnoses. Because overweight and obesity can increase the risk of IR and GDM and is associated with altered FA profiles, ${ }^{12}$ we also stratified our analysis according to pre-pregnancy body mass index (BMI). Furthermore, self-reported dietary consumption was also compared between the two groups of women.

\section{SUBJECTS AND METHODS \\ Subjects}

Between October 2017 and March 2018, all pregnant women attending routine screening at gestational weeks 11-14 at the Prenatal Diagnostic Unit at The National University Hospital (Reykjavik, Iceland) were invited to become participants in the study. Of the 1684 women scheduled for an appointment, 1350 were eligible by being able to answer an Icelandic Food Frequency Questionnaire (FFQ) in addition to their gestational age being between 11 and 14 weeks. Participant flow chart is shown in figure 1. A total of 1015 women agreed to participate $(75 \%)$. Most of the women provided a blood sample during this routine visit, at which time additional tubes were drawn for the purpose of FA analysis. A total of 954 participants provided a non-fasting blood sample. We were able to acquire information on GDM diagnoses from medical data for 853 of these women; hence, the entire analysis consisted of 853 women or $84 \%$ of the enrolled study participants. The source population and cohort has been described in detail in previous publications. $^{1819}$

\section{Dietary intake and characteristics}

During recruitment, the participants answered a short FFQ in electronic format on dietary intake, which also contained questions on age, education, smoking, parity, prepregnancy weight and height. The FFQ assessed the frequency of consumption of 40 food items and beverages and dietary supplement intake, requiring participants to refer to their intake during the previous 3 months. The women chose between 10 potential frequency responses ranging from 'less than once a month' to 'more than 5 times a day'. The FFQ development has previously been described in detail. ${ }^{18} 20-22$

In brief, the FFQ was pilot-tested and compared with results from a 4-day weighed food record with acceptable correlation for most food groups/items (Spearman's correlation $>0.3) .{ }^{20}$ Recent publications from our PREWICE II study have described a dose-dependent association between the consumption of dairy and urine iodine concentration, ${ }^{18}$ wholegrain consumption and alkylresorcinol concentrations (a biomarker for wholegrains) ${ }^{19}$ and reported intake of vitamin D supplements and 25-OH-D in plasma. ${ }^{22}$

\section{Measurement of plasma fatty acids in plasma}

The voluntary blood samples provided at Landspitali University Hospital in weeks $11-14$ by consenting participants were processed within 1 hour after collection to separate plasma from red blood cells and buffy coat via centrifugation at $3000 \mathrm{rpm}$ for $10 \mathrm{~min}$. Plasma was aliquoted into cryotubes and stored in a freezer at $-80^{\circ} \mathrm{C}$ until shipped for FA analysis at the Department of Biology and Biological Engineering, Chalmers University of Technology, Gothenburg, Sweden. The total plasma fatty acid (FA) composition was determined according to the method described by Stråvik et al, ${ }^{23}$ which is a modification of the method described by Masood et al. ${ }^{24} \mathrm{In}$ total, $24 \mathrm{FA}$ were quantified. An internal standard solution (100 $\mu \mathrm{L}$ of $0.1 \mathrm{mg} \mathrm{C23:0} \mathrm{methyl} \mathrm{ester/mL} \mathrm{toluene)}$ was added to $50 \mu \mathrm{L}$ of thawed plasma samples, and 1.8 $\mathrm{mL}$ of acetyl chloride-MeOH solution $(10 \%(\mathrm{v} / \mathrm{v})$ fortified with butylated hydroxytoluene $(2.78 \mu \mathrm{g} / \mathrm{mL})$ was added. Samples were incubated at $70^{\circ} \mathrm{C}$ for $60 \mathrm{~min}$ in a water bath with shaking. Single extraction of fatty acid methyl esters (FAMEs) was carried out by adding $1.5 \mathrm{~mL}$ of hexane. The extraction solvent was evaporated using a vacuum concentrator $\left(125 \mathrm{mbar}, 30^{\circ} \mathrm{C}, 30 \mathrm{~min}\right)$. FAME was dissolved in $200 \mu \mathrm{L}$ of hexane before injection into the GC-FID for analysis. Two water blanks (Milliporepurified water) and six quality controls (pooled plasma) were prepared and run together with the study samples for each batch of a maximum of 50 study samples.

FAMEs were separated using the GC-FID system (Thermo Scientific Focus GC, FID detector, Pal GC-xt 
autosampler, AD-100 $\mathrm{H}_{2}$ generator and a MicroClip XT hydrogen gas alert and a ZA 1500 zero air generator) equipped with a Zebron ZB-FAME column $(20 \mathrm{~m} \times 0.18$ $\mu \mathrm{m}$ ID $\times 0.15 \mu \mathrm{m})$. The oven program was as follows: initial $80^{\circ} \mathrm{C}$ with a 1.5 min hold; ramp: $40^{\circ} \mathrm{C} / \mathrm{min}$ to $160^{\circ} \mathrm{C}$, $5^{\circ} \mathrm{C} /$ min to $185^{\circ} \mathrm{C}$ with a 0 min hold and then $30^{\circ} \mathrm{C} / \mathrm{min}$ to $260^{\circ} \mathrm{C}$ with a 0 min hold. The instrumental condition was as follows: nitrogen as the carrier gas, constant flow, carrier flow $1.25 \mathrm{~mL} / \mathrm{min}$, Inlet temperature $260^{\circ} \mathrm{C}$, split flow $12.5 \mathrm{~mL} / \mathrm{min}$, split ratio: 15 . Detector temperature $260^{\circ} \mathrm{C}$. Gas flow: air $450 \mathrm{~mL} / \mathrm{min}$; hydrogen $35 \mathrm{~mL} /$ min; makeup gas $10 \mathrm{~mL} / \mathrm{min}$. The injection volume was $1 \mu \mathrm{L}$. The concentration of FAs in samples was quantified against external standard calibrations made from GLC-462 mixed FAMEs (Nu-Check Prep, Elysian, Minnesota, USA) dissolved in toluene. The external standard included 24 FAMEs ranging from C12:0 to C24:1. An equal amount of internal standard (C23:0 methyl ester) was added to the external standards as added to the study samples, and all analyte peaks were normalized with the peak of the internal standard before calibration.

\section{Gestational diabetes mellitus diagnoses}

The GDM diagnoses are based on The International Association of the Diabetes and Pregnancy Study Groups (IADPSG) ${ }^{25}$ During the first routine maternal care visit in Iceland (around 10 weeks of pregnancy), women at risk of developing GDM, based on age ( $\geq 40$ years), BMI $\left(\geq 30 \mathrm{~kg} / \mathrm{m}^{2}\right)$, ethnicity and history of diabetes or macrosomia ( $\geq 4500 \mathrm{~g}$ ), are invited to provide a fasting blood sample to measure fasting blood glucose. If results are $\geq 5.1 \mathrm{mmol} / \mathrm{L}$, the women are diagnosed with GDM or in some cases T2D, if fasting blood sugar is $>7 \mathrm{mmol} / \mathrm{L}$ or hemoglobin Alc is $\geq 48 \mathrm{mmol} / \mathrm{mol}$. The rate of women diagnosed with GDM during this early selective screening is unknown in Iceland. However, a study in France also using selective screening and the IADPSG criteria reported an early hyperglycemia rate of $2.3 \%$ in a cohort of almost 800000 women, corresponding to $26.9 \%$ of the women diagnosed with hyperglycemia overall. ${ }^{26}$

Later in pregnancy, usually at weeks 24-28, the women considered at risk of GDM undergo a 2-hour oral glucose tolerance test (OGTT). During the OGTT blood sugar levels are measured during fasting, after 1 hour and after the second hour. ${ }^{27}$ Previously reported rates of GDM diagnoses in Iceland have been in the range of $11.8 \%-16 \% .^{28}{ }^{29}$ Information on GDM diagnoses for this study was gathered from medical records at the National University Hospital. The records did not always differentiate between early detected GDM, GDMA1 (controlled with diet) or GDMA2 (medication needed); therefore, the GDM diagnoses cover all categories.

\section{Statistical analysis}

Data are presented as means and SD for normally distributed variables or median and 10th-90th percentiles for skewed distributions. A t-test for equality of means was used to compare the normally distributed variables, and
Pearson's $\chi^{2}$ test was used to compare dichotomous variables. The Mann-Whitney $U$ test for two independent samples was used to compare differences for skewed variables.

For classification of FA groups, the concentrations of different types of FA were combined to determine the total for SFA, MUFA, PUFA n-6, PUFA n-3 as well as eicosapentaenoic acid (EPA) and docosahexaenoic acid (DHA) especially. Ratios of individual and groups of FA were calculated by dividing their concentration by the total FA concentration.

The value for six of the FA was below the limit of quantification in a few cases. For four of the FA $0.1 \%-0.2 \%$ of the participants had levels below quantification, but for myristoleate (14:1) the rate was 3\% and for docosatetraenoic (22:4) it was $10 \%$. Values below limit of quantification were set to half of the lowest value quantified for an FA in our data.

A linear regression model to compare means was used to evaluate the adjusted difference in FA types, between the women who were diagnosed later with GDM and those who were not.

Multivariate binary logistic regression was used to evaluate the OR of GDM across quartiles of FA types as well as relative FA. P for trend was evaluated by using the median value in each quartile and modeling the plasma FA and relative FA variables as continuous in the regression model. Results from the regression model are presented as multivariate-adjusted. A Spearman's correlation was used to investigate correlations between dietary intake and FA. IBM Statistical Package for Social Sciences for Windows, V.24.0 (Armonk, New York, USA), was used to analyze the data. The level of significance was accepted as $\mathrm{p}<0.05$.

\section{Covariates}

The covariates included in the adjusted models were selected a priori based on their potential influence on GDM diagnoses. ${ }^{30-34}$ In the adjusted linear regression model, covariates were age, prepregnancy BMI $\left(\mathrm{kg} / \mathrm{m}^{2}\right)$, weekly weight gain $(\mathrm{kg} /$ week) and maternal smoking during pregnancy.

The covariates included in our multivariate adjusted models were age; prepregnancy BMI $\left(\mathrm{kg} / \mathrm{m}^{2}\right)$; weekly weight gain $(\mathrm{kg} /$ week); parity $(0,1$ and $\geq 2)$; maternal smoking during pregnancy (yes/no) and family history of diabetes (yes/no/unknown). In cases when missing values for covariates were low $(<5 \%)$, they were imputed using the median or the most probable value, which was the case for prepregnancy BMI. When prepregnancy BMI values were missing $(2.6 \%$ overall, $7.6 \%$ of the women diagnosed with GDM), values were imputed using the median or the most probable value based on BMI at the first maternal care visit. For family history of diabetes (missing=15\%), missing values were accounted for by use of the missing category for covariate adjustment.

Medical records provided information on gestational age and maternal weight at maternal care visits. From 
Table 1 Characteristics of the women in PREWICE II

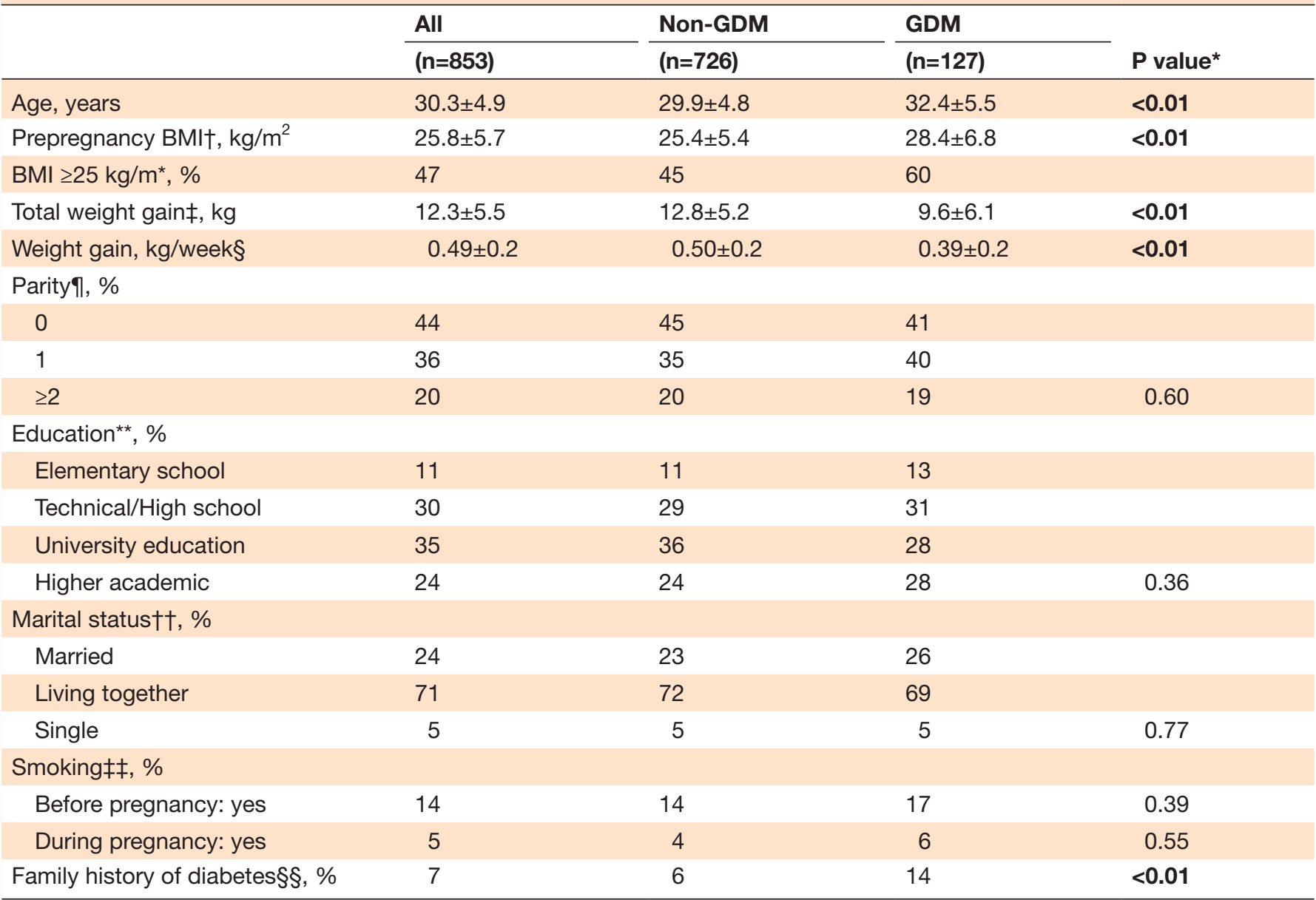

Data are presented as means $\pm S D$ or ratios.

*Differences between non-GDM and GDM using t-test for equality of means, Pearson's $\chi^{2}$ test and Mann-Whitney $U$ test for two independent samples. Bold text indicates a statistically significant difference with a p-value $\leq 0.05$.

†Information on prepregnancy BMI is missing for 22 women.

łInformation on weight gain is missing for 45 women. Total weight gain is the difference between measured weight at first and last maternal care visit.

§Weekly weight gain is the total weight gain divided by number of weeks between first and last maternal care visit.

ๆlnformation on parity is missing for 6 women.

**Information on education is missing for 5 women.

††Information on marital status is missing for 21 women.

łłInformation on smoking is missing for 6 women.

$\S \S$ Information on family history of diabetes is missing for 128 women.

BMI, body mass index; GDM, gestational diabetes mellitus; PREWICEII, Pregnant women in Iceland II.

these data, we were able to calculate total weight gain and weight gain per week by dividing total weight gain with the number of weeks between visits.

Self-reported prepregnancy weight and height from the FFQs was used to calculate prepregnancy BMI $(\mathrm{kg} /$ $\mathrm{m}^{2}$ ). A BMI $<18.5 \mathrm{~kg} / \mathrm{m}^{2}$ was defined as underweight, $18.5-24.9 \mathrm{~kg} / \mathrm{m}^{2}$ as normal weight, $25-29.9 \mathrm{~kg} / \mathrm{m}^{2}$ as overweight and $\geq 30.0 \mathrm{~kg} / \mathrm{m}^{2}$ as obese.

\section{RESULTS}

Characteristics of the participants are presented in table 1 .

The mean age of all participants was 30 years, and $44 \%$ were nullipara. In total, $59 \%$ had a university-level or higher academic education, and 14\% smoked before pregnancy. The prevalence of GDM diagnoses was $14.9 \%$ $(n=127)$. The women diagnosed with GDM were more likely to be older and have a higher prepregnancy BMI. They were, therefore, also more likely to be overweight or obese prior to pregnancy (59.8\%) compared with women without GDM (44.6\%).

The concentrations of total and relative SFA, MUFA, PUFA n- 6 and n- 3 at gestational weeks 11-14 are provided in table 2, whereas the concentrations of individual FAs for women with and without later GDM diagnoses are presented in online supplemental table 1.

The total concentration of FA was significantly higher in women diagnosed with GDM, as were the concentrations 
Table 2 Fatty acid concentrations at gestational weeks 11-14 in women with and without GDM diagnosis later in pregnancy, also stratified by BMI*

\begin{tabular}{|c|c|c|c|c|c|c|c|}
\hline & Non-GDM & GDM & \multirow[b]{3}{*}{$P$ value } & \multirow{2}{*}{$\begin{array}{l}\text { Mean adjusted } \\
\text { difference }\end{array}$} & Non-GDM & GDM & \multirow[b]{3}{*}{$P$ value } \\
\hline & \multicolumn{2}{|c|}{ Median (10th-90th percentile) } & & & \multicolumn{2}{|c|}{ Median (10th-90th percentile) } & \\
\hline & Total $\mu \mathrm{g} / \mathrm{mL}$ & & & $\mu \mathrm{g} / \mathrm{mL}(95 \% \mathrm{Cl}) \dagger$ & Ratio \%¥ & & \\
\hline All & $(n=726)$ & $(n=127)$ & & & $(n=726)$ & $(n=127)$ & \\
\hline SFA & $906(712-1166)$ & $966(747-1230)$ & $<0.01$ & 37 (1 to 75$)$ & $34(32-36)$ & $33(31-36)$ & 0.39 \\
\hline MUFA & $688(521-928)$ & $784(562-1041)$ & $<0.01$ & 75 (40 to 110$)$ & $26(23-29)$ & $27(24-31)$ & $<0.01$ \\
\hline PUFA n-6 & 955 (793-1178) & $989(813-1188)$ & 0.02 & $21(-11$ to 52$)$ & $36(32-40)$ & $35(31-38)$ & $<0.01$ \\
\hline PUFA n-3 & $128(94-177)$ & $134(99-180)$ & 0.05 & $-0,3(-8$ to 7$)$ & $4.7(3.7-6.2)$ & $4.6(3.8-5.9)$ & 0.38 \\
\hline $\mathrm{EPA}+\mathrm{DHA}$ & $93(66-135)$ & $97(73-133)$ & 0.11 & $-2(-8$ to 5$)$ & $3.4(2.5-4.8)$ & $3.4(2.6-4.5)$ & 0.40 \\
\hline $\begin{array}{l}\text { Total fatty } \\
\text { acids }\end{array}$ & 2681 (2174-3392) & 2898 (2287-3632) & $<0.01$ & 133 (33 to 233 ) & - & - & \\
\hline$B M I<25 \mathrm{~kg} / \mathrm{m}^{2}$ & $(n=396)$ & $(n=44)$ & & & $(n=396)$ & $(n=44)$ & \\
\hline SFA & 887 (705-1153) & 941 (730-1282) & 0.17 & 45 (-11 to 100$)$ & $34(32-36)$ & $34(31-36)$ & 0.54 \\
\hline MUFA & 660 (516-906) & 753 (522-1034) & $<0.01$ & 88 (38 to 138$)$ & 25 (22-29) & $27(23-30)$ & $<0.01$ \\
\hline PUFA n-6 & 947 (789-1178) & 969 (769-1203) & 0.18 & 24 (-23 to 72$)$ & $36(32-40)$ & $35(32-38)$ & 0.02 \\
\hline PUFA n-3 & $126(93-178)$ & $133(99-176)$ & 0.14 & $3(-8$ to 15$)$ & $4.7(3.8-6.2)$ & $4.7(3.8-6.0)$ & 0.99 \\
\hline $\mathrm{EPA}+\mathrm{DHA}$ & $92(64-133)$ & $98(73-136)$ & 0.14 & $2(-7$ to 12$)$ & $3.4(2.5-4.8)$ & $3.5(2.6-5.0)$ & 0.87 \\
\hline $\begin{array}{l}\text { Total fatty } \\
\text { acids }\end{array}$ & $2615(2127-3340)$ & $2773(2178-3701)$ & 0.04 & 161 (14 to 307$)$ & - & - & \\
\hline$B M I>25 \mathrm{~kg} / \mathrm{m}^{2}$ & $(n=324)$ & $(n=77)$ & & & $(n=324)$ & $(n=77)$ & \\
\hline SFA & 918 (727-1186) & 973 (766-1231) & 0.01 & $30(-23$ to 83$)$ & $34(31-36)$ & $33(31-36)$ & 0.68 \\
\hline MUFA & 717 (535-962) & $822(570-1092)$ & $<0.01$ & 60 (12 to 109$)$ & $26(23-30)$ & 27 (24-32) & $<0.01$ \\
\hline PUFA n-6 & 963 (796-1180) & 990 (814-1191) & 0.07 & 16 (-27 to 59$)$ & $36(32-39)$ & $35(30-38)$ & 0.01 \\
\hline PUFA n-3 & 131 (95-181) & $134(104-182)$ & 0.34 & $-3(-13$ to 6$)$ & $4.7(3.7-6.2)$ & $4.6(3.8-5.9)$ & 0.30 \\
\hline $\mathrm{EPA}+\mathrm{DHA}$ & $96(67-136)$ & $95(74-132)$ & 0.52 & $-5(-12$ to 3$)$ & $3.5(2.6-4.7)$ & $3.3(2.5-4.5)$ & 0.27 \\
\hline $\begin{array}{l}\text { Total fatty } \\
\text { acids }\end{array}$ & 2769 (2210-3412) & $2944(2323-3632)$ & $<0.01$ & $103(-35$ to 240$)$ & - & - & \\
\hline
\end{tabular}

Bold text indicates a statistically significant difference with a p-value $\leq 0.05$.

*BMl information is missing for 12 women.

†Adjusted for age, prepregnancy BMI, weekly weight gain and smoking during pregnancy when all women are included. No adjustment for prepregnancy BMI when stratifying for BMI.

$\ddagger$ Relative FA concentrations as a ratio of total FA.

BMI, body mass index; DHA, docosahexaenoic acid; EPA, eicosapentaenoic acid; FA, fatty acids; GDM, gestational diabetes mellitus; MUFA, monounsaturated

fatty acids; PUFA, polyunsaturated fatty acids; SFA, saturated fatty acids.

of all types of FA, except for long n-3 FAs EPA+DHA. When stratified by prepregnancy BMI $\left(<25 \mathrm{~kg} / \mathrm{m}^{2}\right.$ vs $\geq 25 \mathrm{~kg} / \mathrm{m}^{2}$ ), the same tendency toward a higher concentration of total FA and MUFA in women who later were diagnosed with GDM was observed in both groups. When comparing relative FA concentrations of women later diagnosed with GDM with those who were not, MUFA was significantly higher, and PUFA n-6 was significantly lower for the women who later developed GDM. This difference remained after stratifying by prepregnancy BMI $\left(<25 \mathrm{~kg} / \mathrm{m}^{2}\right.$ vs $\left.\geq 25 \mathrm{~kg} / \mathrm{m}^{2}\right)$.

Table 3 shows the OR for developing GDM according to quartiles of FA concentrations (total plasma concentration and ratio of total plasma concentration).

When examining the total concentration, a significant trend toward increased odds of GDM was noted with higher concentrations of MUFA, PUFA n- 6 and total FA. However, when FA was expressed as a ratio of total plasma concentration, increased odds for GDM were seen with a higher ratio of MUFA. The odds of GDM were lower in the highest quartile of PUFA n- 6 ratio compared with the lowest quartile, although $\mathrm{p}$ for trend did not reach significance. No association was observed between PUFA n-3 and GDM; neither for total concentration nor the ratio of total plasma PUFA n-3.

Table 4 shows a comparison of dietary intake in early pregnancy between the women who were later diagnosed with GDM and those who were not.

Women who were later diagnosed with GDM had a significantly lower intake of fatty fish and skimmed milk compared with women who did not develop GDM. They also tended to use a higher proportion of saturated fat but a lower proportion of vegetable oil when cooking ( $50 \%$ vs $29 \% \mathrm{p}=0.06)$ versus $(50 \%$ vs $71 \% \mathrm{p}=0.06)$, respectively. Reported intake of omega-3 supplements also tended to be lower for women who were later diagnosed with GDM, with differences close to significance. Other differences observed in dietary intake between the two groups included a lower frequency intake of whole grains, fruit juice, beans, nuts, seeds and coffee during 
Table 3 The associations between quartiles of fatty acid concentrations and ratios with GDM diagnoses

\begin{tabular}{|c|c|c|c|c|c|c|}
\hline \multirow[b]{2}{*}{$\mathrm{N}=853$} & \multicolumn{3}{|l|}{ Total plasma* } & \multicolumn{3}{|c|}{ Ratio† of total plasma* } \\
\hline & Median $(\mu \mathrm{g} / \mathrm{mL})$ & No. cases $(\%) / n$ & OR $(95 \% \mathrm{Cl})$ & Median \% & No. cases $(\%) / n$ & OR $(95 \% \mathrm{Cl})$ \\
\hline \multicolumn{7}{|l|}{ SFA quartile } \\
\hline SFA-Q2 & 855 & $28(13.1) / 214$ & 1.05 (0.55 to 1.99$)$ & 33.0 & $29(13.5) / 215$ & 0.67 (0.37 to 1.22$)$ \\
\hline SFA-Q3 & 970 & $33(15.5) / 213$ & 1.11 (0.58 to 2.13$)$ & 34.0 & $34(16.1) / 211$ & 1.14 (0.64 to 2.03$)$ \\
\hline \multicolumn{7}{|l|}{ MUFA quartile } \\
\hline MUFA-Q1 & 541 & $21(9.9) / 213$ & 1.00 & 23.1 & $16(7.5) / 213$ & 1.00 \\
\hline MUFA-Q2 & 646 & $21(9.8) / 214$ & 0.77 (0.39 to 1.53$)$ & 25.0 & $19(8.9) / 214$ & $0.89(0.42$ to 1.87$)$ \\
\hline MUFA-Q3 & 750 & $29(13.6) / 213$ & 0.87 (0.45 to 1.70$)$ & 26.6 & $37(17.4) / 213$ & 1.82 (0.94 to 3.52$)$ \\
\hline PUFA n-6-Q1 & 812 & $26(12.2) / 213$ & 1.00 & 32.2 & $41(19.2) / 213$ & 1.00 \\
\hline PUFA n-6-Q2 & 916 & $26(12.1) / 214$ & $0.94(0.49$ to 1.81$)$ & 34.6 & $36(16.7) / 215$ & 1.03 (0.58 to 1.81$)$ \\
\hline PUFA n-6-Q3 & 1009 & $28(13.1) / 213$ & 1.02 (0.54 to 1.92$)$ & 36.5 & $34(16.0) / 212$ & $1.08(0.61$ to 1.91$)$ \\
\hline PUFA n-6-Q4 & 1161 & $47(22.1) / 213$ & 1.67 (0.94 to 2.99$)$ & 38.9 & $16(7.5) / 213$ & $0.47(0.24$ to 0.94$)$ \\
\hline P-trend & & & 0.046 & & & 0.065 \\
\hline \multicolumn{7}{|c|}{ PUFA n-3 quartile } \\
\hline PUFA n-3-Q1 & 97 & $22(10.3) / 213$ & 1.00 & 3.8 & $31(14.6) / 213$ & 1.00 \\
\hline PUFA n-3-Q2 & 120 & $34(16.0) / 213$ & $1.62(0.85$ to 3.07$)$ & 4.4 & $37(17.3) / 214$ & 1.13 (0.63 to 2.02$)$ \\
\hline PUFA n-3-Q3 & 140 & $35(16.4) / 214$ & $1.22(0.64$ to 2.34$)$ & 5.0 & $33(15.5) / 213$ & 0.97 (0.53 to 1.79$)$ \\
\hline \multicolumn{7}{|l|}{$\begin{array}{l}\text { Total plasma } \\
\text { concentration }\end{array}$} \\
\hline Total FA-Q3 & 2886 & $32(15.0) / 213$ & 1.10 (0.59 to 2.07$)$ & - & - & - \\
\hline Total FA-Q4 & 3323 & $50(23.5) / 213$ & 1.76 (0.98 to 3.16$)$ & - & - & - \\
\hline P-trend & & & 0.014 & & & \\
\hline
\end{tabular}

Bold text indicates a statistically significant difference with a $p$-value $\leq 0.05$.

${ }^{*}$ Adjusted for age, prepregnancy BMI, parity, weekly weight gain, smoking during pregnancy, family history of diabetes.

tRelative FA concentrations as a ratio of total FA.

BMI, body mass index; FA, fatty acids; GDM, gestational diabetes mellitus; MUFA, monounsaturated fatty acids; PUFA, polyunsaturated fatty acids;

SFA, saturated fatty acids.

early pregnancy in women who later were diagnosed with GDM.

There were no clear correlations between dietary intake and FA concentrations except in the case of fatty fish and omega- 3 supplements, both of which correlated positively with concentrations of PUFA n- 3 and EPA+DHA (online supplemental tables 2 and 3) pregnancy (59.8\%) compared with women without GDM (44.6\%).

One limitation of our study is that we did not have exact data at the time of diagnoses for our GDM cases. As subjects with known risk factors are more likely to be diagnosed early (online supplemental table 4), we examined the concentrations of total and relative SFA, MUFA,
PUFA n-6 and n-3, excluding all women with known risk factors that prompt early GDM screening (BMI $\geq 30 \mathrm{~kg}$ / $\mathrm{m}^{2}$, age $\geq 40$ years and parity $\geq 1$, to exclude all women with previous GDM/macrosomia).

\section{DISCUSSION}

We found that the total concentrations of plasma FAs, as well as total MUFA and MUFA ratio measured at 11th14th week of pregnancy, were significantly higher and PUFA n-6 ratios lower in women who were later diagnosed with GDM, independent of the women's BMI. The fact that stratifying by BMI did not alter our results is 
Table 4 FFQ reported weekly intake of foods at 11 th-14th week of pregnancy ${ }^{*}$

\begin{tabular}{|c|c|c|c|}
\hline \multirow[b]{2}{*}{ FFQ, frequency per week $\uparrow$} & Non-GDM $(n=742)$ & GDM $(n=123)$ & \multirow[b]{2}{*}{ P value } \\
\hline & \multicolumn{2}{|c|}{ Median (10th-90th percentile) } & \\
\hline Fish, fatty & $0.5(0.1-1.0)$ & $0.1(0.1-1.0)$ & $<0.01$ \\
\hline Fish, lean & $1.0(0.1-2.5)$ & $1.0(0.1-2.5)$ & 0.39 \\
\hline Omega-3 supplements & $1.0(0.3-14.1)$ & $0.3(0.3-10.9)$ & 0.09 \\
\hline Red meat & $1.0(0.1-2.5)$ & $1.0(0.1-2.5)$ & 0.94 \\
\hline Poultry & $1.0(0.1-2.5)$ & $1.0(0.1-2.5)$ & 0.41 \\
\hline Processed meat & $0.5(0.1-2.5)$ & $0.5(0.1-1.3)$ & 0.39 \\
\hline Whole milk & $0.1(0.1-5.0)$ & $0.1(0.1-7.0)$ & 0.68 \\
\hline Low fat milk & $1.0(0.2-7.1)$ & $0.6(0.2-14.1)$ & 0.55 \\
\hline Skimmed milk & $0.2(0.2-1.7)$ & $0.2(0.2-1.1)$ & 0.02 \\
\hline Sour dairy & $2.5(0.1-7.0)$ & $2.5(0.1-7.0)$ & 0.18 \\
\hline Cheese & $5.0(1.0-14.0)$ & $5.0(1.0-14.0)$ & 0.11 \\
\hline Butter on bread & $5.0(0.5-14.0)$ & $5.0(0.3-7.0)$ & 0.42 \\
\hline Butter for cooking & $1.0(0.1-5.0)$ & $2.5(0.1-5.4)$ & 0.76 \\
\hline Vegetable oil for cooking & $5.0(1.0-7.0)$ & $2.5(0.3-7.0)$ & 0.07 \\
\hline French fries and chips & $0.5(0.3-2.5)$ & $0.5(0.1-2.5)$ & 0.53 \\
\hline Cakes, sweets, ice cream and cookies & $3.5(1.0-8.0)$ & $3.0(0.6-7.5)$ & 0.11 \\
\hline Soft drinks & $1.5(0.2-7.1)$ & $2.6(0.2-10.8)$ & 0.44 \\
\hline Fruit juice & $1.0(0.1-7.0)$ & $0.5(0.1-7.0)$ & 0.01 \\
\hline Fruits and vegetables & $14.0(5.0-39.0)$ & $14.0(3.4-39.0)$ & 0.12 \\
\hline Beans, nuts and seeds & $0.5(0.1-5.0)$ & $0.5(0.1-2.5)$ & 0.01 \\
\hline Wholegrains & $6.0(1.2-15.0)$ & $4.0(0.5-19.2)$ & $<0.01$ \\
\hline White bread & $2.5(0.1-7.0)$ & $2.5(0.1-7.0)$ & 0.97 \\
\hline Coffee & $0.5(0.10-14.0)$ & $0.1(0.1-7.0)$ & 0.01 \\
\hline
\end{tabular}

${ }^{*}$ Data are presented as medians and percentiles (10th-90th).

†FFQ information on intake is missing for six participants.

$\ddagger$ Differences between non-GDM and GDM using the Mann-Whitney U test for two independent samples. Bold text indicates a statistically significant difference with a $p$-value $\leq 0.05$.

FFQ, Food Frequency Questionnaire; GDM, gestational diabetes mellitus.

important to note because obesity, IR and FA profiles in GDM are strongly inter-related. ${ }^{12}$

In most previous studies on FA profiles in pregnancy cohorts, FA analysis was performed during or after GDM diagnoses. ${ }^{12}$ These studies found that SFA concentrations appeared to be higher in women diagnosed with GDM when compared with a control group and that PUFA n-6 and PUFA n-3 concentrations were both lower in women with GDM. ${ }^{12}$ A recent meta-analysis similarly reported that women with GDM had higher total concentrations of FFAs in the second and third trimester compared with women without GDM, with concentrations decreasing as pregnancy progressed. ${ }^{35}$

The results of the few studies that have investigated FA concentrations in early pregnancy, prior to GDM diagnosis, agree with the present study's findings, showing higher total concentrations of SFA ${ }^{13-15}$ and MUFA ${ }^{1315}$ as well as PUFA $n-6^{16}$ and PUFA $n-3^{13}$ in women who were later diagnosed with GDM compared with those who were not. On the other hand, some of these studies reported lower PUFA n- $6^{1315}$ and PUFA n- $3^{15-17}$ concentrations in women who later received a GDM diagnosis.

FA profiles have been proposed as a means of predicting later T2D diagnosis in non-pregnant populations, where higher relative concentrations of FFA, ${ }^{36}$ PUFA n- $6,{ }^{37}$ MUFA $^{36} 37$ and SFA ${ }^{36} 37$ have been associated with an increased risk of impaired glucose tolerance and T2D risk. These studies have reported similar results as observed for circulating FA in the pregnant population in our study. Associations between higher PUFA n-6 relative to total FA and increased insulin sensitivity have also been found in previous studies in non-pregnant populations,${ }^{36}$ which is in accordance with the results seen in the present pregnancy cohort.

The FA profiles may be a result of differences in intake or absorption of both carbohydrates and fat. ${ }^{12}$ Plasma MUFA and SFA concentrations do not only represent dietary intake as FAs can be synthesized endogenously, mainly from carbohydrates, which is then referred to as de novo lipogenesis. ${ }^{38} 39$ Other factors that could influence FA profile are FA synthesis 
and incorporation of FA into cell membranes. It remains unclear how the plasma total FA profile is physiologically associated with diabetes. Lipogenesis is stimulated by insulin and suppressed by the hormones glucagon and epinephrine. Some studies have suggested that higher FFA may alter insulin signalling, secretion and glucose production. ${ }^{40}{ }^{41}$ It is, therefore, possible that an abnormal increase of insulin in the blood may lead to higher FA concentrations and vice versa.

Some differences were found in food consumption in the first trimester between women with and without GDM diagnoses, and it is not clear how this difference might be reflected in the plasma FA profile. It could have been expected to see a difference in EPA and DHA concentrations between the two groups because women who later were diagnosed with GDM had a less frequent intake of both fatty fish and omega-3 supplements. However, because FA can be synthesized endogenously from excess carbohydrates, the overall quality of the diet, including carbohydrate quality and amount consumed, might explain some of the difference observed in FA concentration between the two groups, overall carbohydrate quality being one. ${ }^{1921} 42$

As we have previously reported in this cohort, the women who were later diagnosed with GDM had lower quality of carbohydrate intake as they had a lower intake of wholegrains (estimated by biomarkers). ${ }^{19}$ Intake of soft drinks also tended to be greater for women diagnosed with GDM as well as use of saturated fat for cooking, even though the difference was not statistically significant. This could suggest that the overall diet quality in early pregnancy was lower among the women later diagnosed with GDM.

In summary, a stronger association has been observed between plasma FA and diabetes risk compared with dietary intake estimates. ${ }^{37}$ It is important to note that different sources of FA measurements can represent varying dietary intake periods, such as adipose tissue (long-term FA intake 1-1.5 years), skeletal muscle cells, erythrocytes (120 days), serum, total plasma, phospholipids (1-2 weeks ${ }^{12}$ ), cholesteryl esters and FFAs. ${ }^{37}$ Erythrocytes have been claimed as a preferable option to evaluate differences in recent $\mathrm{FA}$ intake, at least regarding PUFA n-3. ${ }^{39}$ However, FA from erythrocytes and plasma have been found to correlate. ${ }^{37}$ In our study, we analyzed total plasma FA, which includes the FAs from cholesteryl esters, phospholipids, triacyclglycerols and FFA thought to represent very recent intake (1-2 weeks), whereas the answers in the FFQ covered intake during the previous 3 months.

It might be considered a limitation that our participants were not fasting. This might have resulted in lower concentrations of FFA because they are reduced in response to higher insulin levels postmeals ${ }^{43}$ and makes a comparison with other studies challenging. However, comparisons of our results with other studies may be affected by the non-fasting state of our participants and by the difference in methodology used when analysing FA profiles. Another limitation is that we did not have exact information on date of diagnoses, thereby part of our
GDM cases may have received their diagnosis at or close to drawing of the blood sample in which FA profiles were quantified. However, we did see a similar trend in the results (online supplemental 4) when we ran our analysis excluding all women with known risk factors that prompt early GDM screening (BMI, age and previous GDM/ macrosomia). We therefore believe that this limitation did not majorly affect our main results.

The strength of our study is that we analyzed plasma FA early in pregnancy, in addition to acquiring subjective data on dietary intake. Our study also features prospectively collected data from a large sample size of 853 pregnant women with high participation rate $(75 \%)$. We report both total concentrations of all FA subgroups as well as their ratios. We adjusted for BMI, and stratified our FA results by BMI, a process that, to our knowledge, has not been previously performed in a pregnancy cohort.

In conclusion, we found that women who were later diagnosed with GDM had a higher concentration of total plasma FA, total MUFA and MUFA ratios as well as lower PUFA n-6 ratios in early pregnancy, independent of the women's BMI, compared with women who remained free of GDM. The women who were not diagnosed with GDM also tended to have better diet quality in early pregnancy. These results suggest that FA biomarkers in early pregnancy may predict GDM. However, further studies are required to confirm this hypothesis.

Acknowledgements The authors would like to thank the staff at the Prenatal Diagnostic Unit at the National University Hospital in Iceland for their hospitality and positive attitudes, which contributed significantly to the recruitment of participants for this study.

Contributors IG, ITH and HH designed the research. EAT and IG conducted the research. RL, LH, ITH and HH provided essential materials. EAT, TIH and IG analyzed data and performed statistical analysis. EAT, TIH and IG wrote the paper. EAT, TIH and IG had primary responsibility for final content. All authors read, edited and approved the final manuscript.

Funding This study was funded by the University of Iceland Research Fund (HI18080069) and the Science Fund of The National University Hospital in Iceland (798381 and 893911).

Competing interests None declared.

Patient consent for publication Not required.

Ethics approval The study was approved by the National Bioethics Committee (VSN-17-057-S1) and the Medical Directorate of Landspitali University Hospital (LSH 5-17). Written consents were obtained from the participants.

Provenance and peer review Not commissioned; externally peer reviewed.

Data availability statement No data are available. Data are not in a repository.

Supplemental material This content has been supplied by the author(s). It has not been vetted by BMJ Publishing Group Limited (BMJ) and may not have been peer-reviewed. Any opinions or recommendations discussed are solely those of the author(s) and are not endorsed by BMJ. BMJ disclaims all liability and responsibility arising from any reliance placed on the content. Where the content includes any translated material, BMJ does not warrant the accuracy and reliability of the translations (including but not limited to local regulations, clinical guidelines, terminology, drug names and drug dosages), and is not responsible for any error and/or omissions arising from translation and adaptation or otherwise.

Open access This is an open access article distributed in accordance with the Creative Commons Attribution Non Commercial (CC BY-NC 4.0) license, which permits others to distribute, remix, adapt, build upon this work non-commercially, and license their derivative works on different terms, provided the original work is 
properly cited, appropriate credit is given, any changes made indicated, and the use is non-commercial. See: http://creativecommons.org/licenses/by-nc/4.0/.

\section{ORCID iD}

Ellen Alma Tryggvadottir http://orcid.org/0000-0002-9687-3425

\section{REFERENCES}

1 Zhu Y, Zhang C. Prevalence of gestational diabetes and risk of progression to type 2 diabetes: a global perspective. Curr Diab Rep 2016;16:7.

2 Nijs H, Benhalima K. Gestational diabetes mellitus and the longterm risk for glucose intolerance and overweight in the offspring: a narrative review. J Clin Med 2020;9:599.

3 Mizgier M, Jarzabek-Bielecka G, Mruczyk K. Maternal diet and gestational diabetes mellitus development. J Matern Fetal Neonatal Med 2019:1-10.

4 Gao F, Cui C-Y. Dietary cholesterol intake and risk of gestational diabetes mellitus: a meta-analysis of observational studies. J Am Coll Nutr 2021:1-9.

5 Khaire A, Wadhwani N, Madiwale S, et al. Maternal fats and pregnancy complications: implications for long-term health. Prostaglandins Leukot Essent Fatty Acids 2020;157:102098.

6 Barbieiri P, Nunes JC, Torres AG, et al. Indices of dietary fat quality during midpregnancy is associated with gestational diabetes. Nutrition 2016;32:656-61.

7 Hodson L, Bickerton AST, McQuaid SE, et al. The contribution of splanchnic fat to VLDL triglyceride is greater in insulin-resistant than insulin-sensitive men and women: studies in the postprandial state. Diabetes 2007:56:2433-41.

8 Walle P, Takkunen M, Männistö V, et al. Alterations in fatty acid metabolism in response to obesity surgery combined with dietary counseling. Nutr Diabetes 2017;7:e285.

9 Homko CJ, Cheung P, Boden G. Effects of free fatty acids on glucose uptake and utilization in healthy women. Diabetes 2003;52:487-91.

10 Chen X, Stein TP, Steer RA, et al. Individual free fatty acids have unique associations with inflammatory biomarkers, insulin resistance and insulin secretion in healthy and gestational diabetic pregnant women. BMJ Open Diabetes Res Care 2019;7:e000632.

11 Sivan E, Homko CJ, Whittaker PG, et al. Free fatty acids and insulin resistance during pregnancy. J Clin Endocrinol Metab 1998;83:2338-42.

12 Taschereau-Charron A, Da Silva MS, Bilodeau J-F, et al. Alterations of fatty acid profiles in gestational diabetes and influence of the diet. Maturitas 2017;99:98-104.

13 Li X, Huang Y, Xing Y, et al. Association of urinary cadmium, circulating fatty acids, and risk of gestational diabetes mellitus: a nested case-control study in China. Environ Int 2020;137:105527.

14 Zhu Y, Tsai MY, Sun Q, et al. A prospective and longitudinal study of plasma phospholipid saturated fatty acid profile in relation to cardiometabolic biomarkers and the risk of gestational diabetes. Am $J$ Clin Nutr 2018;107:1017-26.

15 White SL, Pasupathy D, Sattar N, et al. Metabolic profiling of gestational diabetes in obese women during pregnancy. Diabetologia 2017;60:1903-12.

16 Ogundipe E, Samuelson S, Crawford MA. Gestational diabetes mellitus prediction? a unique fatty acid profile study. Nutr Diabetes 2020;10:36.

17 Zhu Y, Li M, Rahman ML, et al. Plasma phospholipid n-3 and n-6 polyunsaturated fatty acids in relation to cardiometabolic markers and gestational diabetes: a longitudinal study within the prospective NICHD fetal growth studies. PLoS Med 2019;16:e1002910.

18 Adalsteinsdottir S, Tryggvadottir EA, Hrolfsdottir L, et al. Insufficient iodine status in pregnant women as a consequence of dietary changes. Food Nutr Res 2020;64. doi:10.29219/fnr.v64.3653. [Epub ahead of print: 0601 2020].

19 Tryggvadottir EA, Halldorsson TI, Landberg R, et al. Higher Alkylresorcinol concentrations, a consequence of Whole-Grain intake, are inversely associated with gestational diabetes mellitus in Iceland. J Nutr 2021;151:1159-66.

20 Hrolfsdottir L, Halldorsson TI, Birgisdottir BE, et al. Development of a dietary screening questionnaire to predict excessive weight gain in pregnancy. Matern Child Nutr 2019;15:e12639.

21 Hrolfsdottir L, Gunnarsdottir I, Birgisdottir BE, et al. Can a simple dietary screening in early pregnancy identify dietary habits associated with gestational diabetes? Nutrients 2019;11:1868.
22 Magnusdottir KS, Tryggvadottir EA, Magnusdottir OK, et al. Vitamin $D$ status and association with gestational diabetes mellitus in a pregnant cohort in Iceland. Food Nutr Res 2021;65. doi:10.29219/ fnr.v65.5574. [Epub ahead of print: 2303 2021].

23 Stråvik M, Barman M, Hesselmar B, et al. Maternal intake of cow's milk during lactation is associated with lower prevalence of food allergy in offspring. Nutrients 2020;12. doi:10.3390/nu12123680. [Epub ahead of print: 28 Nov 2020].

24 Masood A, Stark KD, Salem N. A simplified and efficient method for the analysis of fatty acid methyl esters suitable for large clinical studies. J Lipid Res 2005;46:2299-305.

25 International Association of Diabetes and Pregnancy Study Groups Consensus Panel, Metzger BE, Gabbe SG, et al. International association of diabetes and pregnancy study groups recommendations on the diagnosis and classification of hyperglycemia in pregnancy. Diabetes Care 2010;33:e98-82.

26 Cosson E, Carbillon L, Valensi P. High fasting plasma glucose during early pregnancy: a review about early gestational diabetes mellitus. Diabetes Res 2017;2017:1-12

27 Clinical guidelines regarding diagnoses and treatment of gestational diabetes 2012

28 Skemman. Thesis: "Meðgöngusykursýki á Íslandi 2015-2017: Tíoni, greiningarskilmerki og afdrif móður og barns", 2018.

29 Læknablaðið. Prescribing physical activity after labour, for women diagnosed with gestational diabetes mellitus, 2020. Available: https://www.laeknabladid.is/tolublod/2019/12/nr/7197

$30 \mathrm{Li} \mathrm{Y,} \mathrm{Ren} \mathrm{X,} \mathrm{He} \mathrm{L,} \mathrm{et} \mathrm{al.} \mathrm{Maternal} \mathrm{age} \mathrm{and} \mathrm{the} \mathrm{risk} \mathrm{of} \mathrm{gestational}$ diabetes mellitus: a systematic review and meta-analysis of over 120 million participants. Diabetes Res Clin Pract 2020;162:108044.

31 Najafi F, Hasani J, Izadi N, et al. The effect of prepregnancy body mass index on the risk of gestational diabetes mellitus: a systematic review and dose-response meta-analysis. Obesity Reviews 2019;20:472-86.

32 Leng J, Li W, Zhang S, et al. GDM women's Pre-Pregnancy Overweight/Obesity and gestational weight gain on offspring overweight status. PLoS One 2015;10:e0129536.

33 Kim MK, Han K, You SY, et al. Prepregnancy smoking and the risk of gestational diabetes requiring insulin therapy. Sci Rep 2020;10:13901.

34 Dode MASdeO, dos Santos IS. Non classical risk factors for gestational diabetes mellitus: a systematic review of the literature. Cad Saude Publica 2009;25 Suppl 3:S341-59.

35 Villafan-Bernal JR, Acevedo-Alba M, Reyes-Pavon R, et al. Plasma levels of free fatty acids in women with gestational diabetes and its intrinsic and extrinsic determinants: systematic review and metaanalysis. J Diabetes Res 2019;2019:1-13

36 Mahendran $\mathrm{Y}$, Cederberg $\mathrm{H}$, Vangipurapu J, et al. Glycerol and fatty acids in serum predict the development of hyperglycemia and type 2 diabetes in Finnish men. Diabetes Care 2013;36:3732-8.

37 Patel PS, Sharp SJ, Jansen E, et al. Fatty acids measured in plasma and erythrocyte-membrane phospholipids and derived by food-frequency questionnaire and the risk of new-onset type 2 diabetes: a pilot study in the European Prospective Investigation into Cancer and Nutrition (EPIC)-Norfolk cohort. Am J Clin Nutr 2010;92:1214-22.

38 I. S. Sobczak A, A. Blindauer C, J. Stewart A. Changes in plasma free fatty acids associated with type-2 diabetes. Nutrients 2019;11:2022.

39 Sun Q, Ma J, Campos H, et al. Comparison between plasma and erythrocyte fatty acid content as biomarkers of fatty acid intake in US women. Am J Clin Nutr 2007;86:74-81.

40 Boden $\mathrm{G}$. Effects of free fatty acids (FFA) on glucose metabolism: significance for insulin resistance and type 2 diabetes. Exp Clin Endocrinol Diabetes 2003;111:121-4.

41 Boden G, Shulman Gl. Free fatty acids in obesity and type 2 diabetes: defining their role in the development of insulin resistance and $\beta$-cell dysfunction. Eur J Clin Invest 2002;32:14-23.

42 Tryggvadottir EA, Medek H, Birgisdottir BE, et al. Association between healthy maternal dietary pattern and risk for gestational diabetes mellitus. Eur J Clin Nutr 2016;70:237-42.

43 Collins SM, Broadney MM, Ghane N, et al. Free fatty acids as an indicator of the Nonfasted state in children. Pediatrics 2019;143:e20183896. 